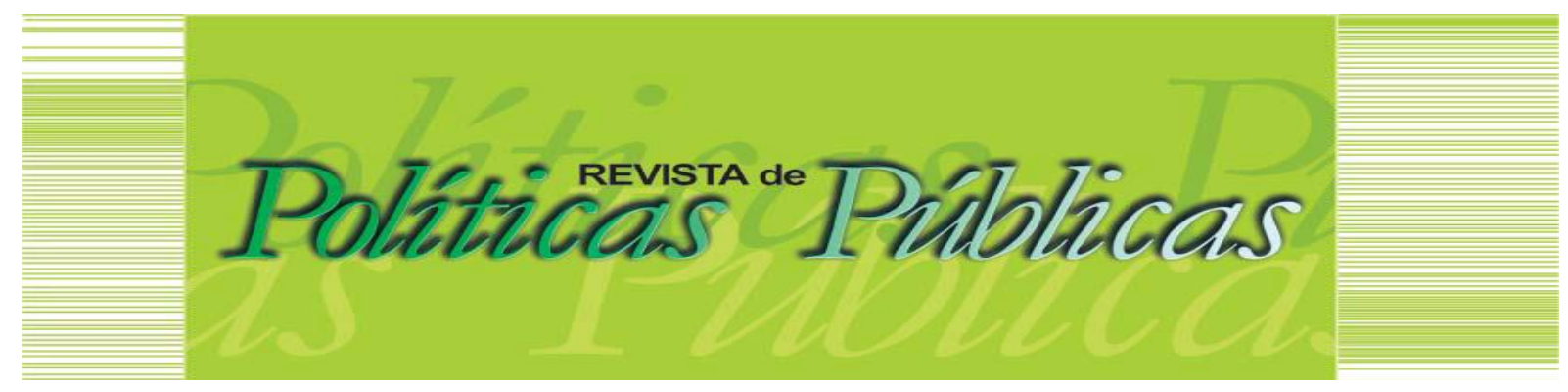

\title{
MINERAÇÃO NA AMAZÔNIA BRASILEIRA: aspectos da presença e avanço do capital na região
}

Gladson Rosas Hauradou ${ }^{1}$

Maria Virgínia Borges Amaral²

\section{Resumo:}

A Região Amazônica brasileira tem sido apresentada ao mundo como reduto de ecossistemas, de espécies de seres vivos ainda não catalogados e dos já catalogados, que expressam potencial econômico abundante para atender aos anseios do ardil capitalista contemporâneo. Sobressai na região, ainda, o histórico processo de extração mineral, que atualmente na condição de commodittes (mercadorias) as quais representam, na sua totalidade, parte importante da produção nacional, $6,8 \%$ do PIB brasileiro o que equivale a $65 \%$ do valor das exportações brasileiras. Neste estudo destacamos que a presença dessas empresas na região conforma um quadro de exploração da riqueza oriunda da natureza de modo que os ganhos reais se voltam para atender à rentabilidade capitalista em detrimento das condições e modos de vida dos sujeitos históricos presentes na região para os quais sobram as consequências deletérias da forma de ser do capital e o acirramento das desigualdades ao nível local em suas muitas dimensões.

Palavras-chave: Capital. Amazônia. Mineração. Commodittes.

MINING IN THE BRAZILIAN AMAZON: aspects of the presence and progress of capital in the region

\begin{abstract}
:
The Brazilian Amazon region has been presented to the world as a stronghold of ecosystems, species of living beings not yet cataloged and those already cataloged, which express abundant economic potential to meet the aspirations of the contemporary capitalist ruse. In the region, there is also the historical process of mineral extraction, which is currently in the condition of commodittes (commodities), which represent, in their totality, an important part of national production, $6.8 \%$ of the Brazilian GDP, equivalent to $65 \%$ of value of Brazilian exports. In this study we emphasize that the presence of these companies in the region constitute a framework for the exploitation of wealth derived from nature so that the real gains are turned to meet the capitalist profitability to the detriment of the conditions and ways of life of the historical subjects present in the region for which the deleterious consequences of the way of being of capital and the intensification of inequalities at the local level in their many dimensions.
\end{abstract}

Keywords: Capital. Amazon. Mining. Commodittes.

Artigo recebido em: 05/02/2019 Aprovado em: 05/05/2019 DOI: http://dx.doi.org/10.18764/2178-2865.v23n1p402-420

\footnotetext{
${ }_{1}^{1}$ Assistente Social. Doutorando do Programa de Pós-Graduação em Serviço Social (PPGSS) da Universidade Federal de Alagoas (UFAL). Bolsista CAPES/ Fundação de Amparo à Pesquisa do Estado de Alagoas (FAPEAL). Docente do Curso de Serviço Social do Instituto de Ciências Sociais, Educação e Zootecnia (ICSEZ) da Universidade Federal do Amazonas (UFAM). Endereço: Estrada Parintins/Macurany, n. 1805, Jacareacanga, Parintins-Amazonas. CEP. 69.153-010. E-mail: gladson@ufam.edu.br

2 Assistente Social. Doutora em Letras e Linguística pelo Programa de Pós-Graduação em Linguistica e Literatura (PPGLL)/UFAL. Docente da Faculdade de Serviço Social (FSSO) e dos PPGSS e PPGLL/UFAL. Endereço: Dep. de Serviço Social, s/n, Tabuleiro do Martins, Maceió - AL. CEP: 57072-970. E-mail: mvirginia39@gmail.com
} 


\section{INTRODUÇÃO}

A Região Amazônica brasileira tem sido apresentada ao mundo como reduto de ecossistemas, de espécies de seres vivos ainda não catalogados e dos já catalogados, que expressam potencial econômico abundante para atender aos anseios do ardil capitalista contemporâneo. Subjaz tal apresentação, conflitos pela terra -- insurgidos por trabalhadores diversos destituídos de propriedades dos meios de produção, munidos, tão somente, de sua força de trabalho. Tais conflitos, ora velados, ora combatidos com brutal violência pelo Estado ou por segmentos da sociedade civil (latifundiários, fazendeiros, grileiros, etc ${ }^{1}$.); o massacre em Eldorado do Carajás ${ }^{2}$ em 1996 e, mais recentemente, em Pau D'arco³, no Pará, são dois dos exemplos trágicos. Sobressai na região, ainda, o histórico processo de extração mineral que, atualmente, na condição de commodittes (mercadorias), representam, na sua totalidade, parte importante da produção nacional, 6,8\% do PIB brasileiro, conforme dados da Conferência das Nações Unidas sobre Comércio e Desenvolvimento, o que equivale a 65\% do valor das exportações brasileiras (UNCTAD, 2014 apud CASTRO, 2016). Essa mercadoria tem sido extraída de várias regiões do país (e da América Latina), mas, particularmente na Amazônia brasileira, sua extração plasma um quadro específico, que apesar de apresentar similaridades em relação a outras áreas onde se processam a coleta de minérios, se realiza num contexto de modos de vida diferenciados, de relações sociais (de produção) também diferenciadas como veremos a seguir.

Ao analisar a mercadoria em O Capital, Marx (1996a, p. 165) destaca que: "A riqueza das sociedades em que domina o modo de produção capitalista aparece como uma 'imensa coleção de mercadorias' e a mercadoria individual como sua forma elementar [...] (grifos do autor)" em seguida, ratifica: "A mercadoria é, antes de tudo, um objeto externo, uma coisa, a qual pelas suas propriedades satisfaz necessidades humanas de qualquer espécie" (1996a, p. 165).

À luz da matriz teórico-metodológica marxiana situamos as commodittes ${ }^{4}$ enquanto mercadorias (extraídas da natureza mediante trabalho humano) as quais visam atender a determinadas necessidades humanas. Assim sendo, consideramos que a transformação da natureza amazônica em mercadoria, dotada de valores de uso (estes inerentes a qualquer mercadoria) e de troca, despreza a presença humana nesse contexto ${ }^{5}$. Diga-se, despreza a presença dos homens e mulheres da Amazônia. Esse desprezo os coloca na condição de apêndice do mercado (POLANYI, 2000) sobre os quais as consequências deletérias (refrações ou reflexos) do processo de exploração recaem de forma brutal.

Entendemos que as commodittes de minério, tendo as empresas de mineração na região amazônica brasileira à frente sob 0 aval do Estado brasileiro, apesar de desempenharem um papel expressivo na produção nacional, legam às sociedades amazônicas o ônus inerente à rentabilidade 
capitalista atendendo a interesses alheios aos reais interesses e necessidades dos sujeitos locais, engendrando um quadro histórico de desigualdades.

Neste estudo destacamos que a presença dessas empresas na região conforma um quadro de exploração da riqueza oriunda da natureza de modo que os ganhos reais se voltam para atender à rentabilidade capitalista em detrimento das condições e modos de vida dos sujeitos históricos presentes na região para os quais sobram as consequências deletérias da forma de ser do capital e o acirramento da desigualdade local em suas muitas dimensões.

São dois os objetivos que evocamos para dar conta das questões postas neste estudo, sendo eles: 1) evidenciar que o avanço e a presença do capital na região, mediados por empresas mineradoras, dissolvem relações sociais pré-existentes e potencializam a agudização das desigualdades em suas muitas dimensões; 2) denunciar que o processo de extração mineral na configuração de commodittes não se voltam para o atendimento das demandas reais das populações locais, restando a estas últimas o ônus de tal processo de exploração enquanto efeito deletério do capital que se expressa em "[...] sua lógica expansionista que, em contato com outras formas de sociabilidade as destrói para submetê-las à sua reprodução ampliada." (LESSA, 1998, p. 138).

Assim, pretende-se destacar alguns aspectos do processo que envolve a presença e 0 avanço do capital na região por meio das empresas de mineração, ressaltando casos em que se constataram os efeitos advindos das atividades de minero-metalurgia.

\section{EXPLORAÇÃO DA/NA AMAZÔNIA6: a natureza sob a lógica Capital}

O processo predatório inerente ao modus operandi capitalista tem avançado em escala planetária aos inúmeros redutos de sociobiodiversidades até então ilesos à rentabilidade orgânica da lógica de mercado. Algumas regiões da Amazônia brasileira, por exemplo, desconheciam esse movimento de expropriação comum às intervenções capitalistas já que na região as relações sociais se desenvolvem de maneira peculiar, pois são imbuídas de uma cosmovisão alheia ao modo de ser capitalista. São, portanto, "[...] Espaços ditos tradicionais, e populações ditas tradicionais, [que] resguardam por isso mesmo, seus traços peculiares, tecidos por uma 'teia de significados' que confere a esses povos o seu caráter de particularidades simbólicas emaranhadas nessa mesma teia de significações." (RANCIARO, 2014, p. 78).

A Amazônia compreende um "[...] vasto complexo de ecossistemas localizado na bacia hidrográfica do rio Amazonas, que tem uma superfície total de pouco mais de 7 milhões de $\mathrm{km}^{2}$ (ou seja, aproximadamente $40 \%$ do continente sul-americano) [...]" (TULIO NETO, 2010, p, 46). Esta, por sua vez, é constituída por oito países dentre os quais, o Brasil (os demais são Bolívia, Peru, Equador, Colômbia, Venezuela) "[...] e, mais pela similaridade vegetal e climática do que pela unidade 
hidrográfica, Guiana e Suriname [...]" (TULIO NETO, 2010, p, 46). Esta é, assim, a Amazônia Continental. (BRASIL, [20--?]).

Enquanto complexo de ecossistemas essa região revela-se, pois o é, como campo rico de possibilidades e potencialidades naturais no qual, ainda, persistem inúmeras formas de apropriação da natureza em favor do capital e em detrimento dos povos (e da vida) nela existentes.

Concordamos com Marx que, na Crítica ao Programa de Gotha, redigida em 1875, ao fazer críticas ao Programa elaborado pelo Partido Operário Alemão, realiza a seguinte afirmação:

[...] A natureza é a fonte dos valores de uso (que são os que verdadeiramente integram a riqueza material!), nem mais nem menos que o trabalho, que não é mais que a manifestação de uma força natural, da força de trabalho do homem. Esta frase encontra-se em todos as cartilhas e só é correta se se subentender que o trabalho é efetuado com os correspondentes objetos e instrumentos. Mas um programa socialista, porém, não deve permitir que tais tópicos burgueses silenciem aquelas condições sem as quais não têm nenhum sentindo. Na medida em que o homem se situa de antemão como proprietário diante da natureza, primeira fonte de todos os meios e objetos de trabalho, e a trata como possessão sua, seu trabalho converte-se em fonte de valores de uso e, portanto, em fonte de riqueza (PAULO NETTO, 2012, p. 425, grifos do autor).

É, pois, nessa perspectiva, que situamos a Amazônia enquanto natureza que se expressa em suas propriedades sociobiodiversas e, portanto, enquanto fonte de valores de uso na qual coexistem relações sociais que são anteriores à forma de ser burguesa e que lidam cotidianamente com os efeitos da presença de agentes externos à região.

$\mathrm{Na}$ condição de fonte dos valores de uso, -- de fonte de riqueza --, o complexo de ecossistemas amazônico tem se revelado historicamente como espaço profícuo e contínuo de expropriação, num processo ditado por empreendimentos nacionais e internacionais os quais têm afetado, sobremaneira, as condições de vida dos povos ali presentes, já que tais intervenções tendem a promover mudanças substantivas no ambiente e nas relações sociais historicamente constituídas na região. São exemplos de intervenções externas as alterações provocadas nas condições ou modos de vida das sociedades pré-colombianas e as intervenções que seguem afetando as sociedades contemporâneas do continente latino-americano.

É emblemática a fala de Freitas (2009) sobre as relações sociais próprias das populações tradicionais na região, que em muito se distanciam da sociabilidade ocidental, ou mais precisamente, da sociabilidade burguesa, e que foram condicionadas ao processo de subsunção ao capital ao longo da história. Essa dinâmica de subsunção "Faz parte da essência do capital [...] [ao] submeter à sua legalidade todas as relações sociais com que se defronta [...]" (LESSA, 1998, p. 138, grifos do autor), ou seja:

Essa sua lógica expansionista que, em contato com outras formas de sociabilidade as destrói para submetê-las à sua reprodução ampliada, faz parte do essencial de sua história desde as feiras medievais até a globalização de nossos dias. Sempre que ocorrer o confronto entre o capital e um complexo social pré-capitalista, desdobrar-se-á uma luta de morte entre 0 "velho" e "novo", na qual as contradições antagônicas que brotam desse confronto tenderão 
sempre a destruir um dos polos. Até hoje, com uma ou outra mediação, o resultado tem sido a vitória do capital (LESSA, 1998, p. 138-139, grifos do autor).

Essa lógica expansionista cuja essência destrutiva submete todas as relações sociais divergentes à reprodução ampliada do capital encontra solo fértil em regiões como a Amazônia onde as relações sociais (e de produção) revelavam e, ainda que de forma residual, revelam-se como um contraponto à forma de ser capitalista. Trata-se, pois, de uma posição diametralmente oposta, por assim dizer.

Para Freitas (2009, p. 22, grifos nossos):

\begin{abstract}
As sociedades tradicionais da região exercitaram, por milênios, a convivência pluricultural interétnica, e plurinacional em sociedades de abundância e de ocupabilidade plena. Pode ser dito que a colonização e o desenvolvimento do capitalismo na Amazônia criaram os problemas regionais, o subdesenvolvimento econômico e sociocultural, inventaram a pobreza e a dependência, além de instituírem a desigualdade estrutural e federativa, de "classes" e de povos.
\end{abstract}

Com efeito, o trato atribuído (pelo olhar e ação do outro, este enquanto agente externo) à região mostra-se herdeiro das formas predatórias de apropriação das riquezas naturais, com as riquezas humanas aí incluídas, cuja orientação se dá atualmente sob lógica de rentabilidade inerente ao modus operandi capitalista enquanto força motriz dos problemas regionais, [do] subdesenvolvimento econômico e sociocultural, [e da] pobreza na região.

Freitas (2009, p. 22) destaca, ainda, que:

Os homens da Amazônia pré-colonial não eram só caçadores e coletores. Eram artesãos, navegadores e possuidores de um nível técnico capaz de dar conta das necessidades de reprodução de grandes contingentes humanos e do domínio cultural sobre os territórios litorâneos, centrais e ribeirinhos do espaço físico.

Ao verticalizarmos nossa atenção para a Amazônica brasileira7 nos deparamos com questões, as mais diversas, que perpassam as relações de homens e mulheres, in loco, cujas vidas são impactadas cotidianamente dada a presença de agentes exógenos à região. A exogenia que se expressa nas diferentes investidas do capital na região pode ser apreendida sob a denominação, conforme Teixeira (1998), de modernização conservadora. Concordamos com a autora, pois de acordo com suas investigações, a Amazônia tem se apresentado como "[...] uma região em cujos municípios, principalmente naqueles dos grandes projetos, desfilam crianças que na rua imploram por um pouco de comida, adultos coletando alimento no lixo, [...] índios se prostituindo nos bordéis improvisados [...]". (TEIXEIRA, 1998, p. 103); some-se, ainda, à violência sexual infantil nas suas distintas manifestações. Fazer frente a essas questões exige estratégias hercúleas dos amazônidas. Exige, sobretudo, organização e mobilização coletiva consubstanciada de modo a articular todos os pontos fragmentários -- singulares -- em demandas coletivas, pois "Adesões singulares nada representam diante da lógica de 
avanço no espaço amazônico, determinado de fora para dentro - tanto de fora da região quanto do próprio país, sobretudo do estrangeiro" (PINTO, 2018).

3 EXPLORAÇÃO MINERAL NA AMAZÔNIA BRASILEIRA: presença e avanço do capital

Ao avançar para novas fronteiras o Grande Capital tem promovido expressiva agressão tanto nas dimensões objetivas quanto subjetivas dos sujeitos locais subsumidos por esse movimento predatório, agora com caráter globalizante num movimento tendencial de homogeneização das relações sociais de produção.

Nos dizeres de Antunes (2001, p. 36, grifo do autor):

[...] entre tantas destruições de forças produtivas, da natureza e do meio ambiente, há também, em escala mundial, uma ação destrutiva contra a força humana de trabalho, que encontra-se hoje na condição de precarizada ou excluída. Em verdade, estamos presenciando a acentuação daquela tendência que István Mészáros sintetizou corretamente, ao afirmar que o capital, desprovido de orientação humanamente significativa, assume, em seu sistema metabólico de controle social, uma lógica que é essencialmente destrutiva, onde o valor de uso das coisas é totalmente subordinado ao seu valor de troca.

Essa lógica sócio-metabólica destrutiva desconsidera as relações sociais, configuradas sócio historicamente, ao instituir novas relações metamorfoseadas em relações de mercado que, com a vênia do autor supracitado, com sua "[...] lógica que é essencialmente destrutiva, [...] o valor de uso das coisas é totalmente subordinado ao seu valor de troca". (ANTUNES, 2001, p. 36).

Conforme Mészáros (1995, p. 117 apud LESSA, 1998, p. 139, grifos do autor) o:

[...] capital enquanto tal nada mais é que uma dinâmica, um modo e meio de mediação reprodutiva que a tudo abarca e domina [...] É um sistema claramente identificável de mediações o qual, nas suas formas adequadamente desenvolvidas, subordina estritamente todas as funções sócio-reprodutivas - das relações de gênero e de família às relações materiais de produção, e até mesmo a criação de obras de arte - à exigência absoluta de expansão do capital, isto é, da sua própria expansão contínua e reprodução ampliada enquanto um sistema sócio-metabólico de mediação.

Nessa perspectiva, o avanço do capital na região amazônica tem se dado sob a tutela do Estado ${ }^{8}$ Brasileiro numa relação que expropria, anula, dissolve relações seculares e sobrepõe um modo de ser alheio à cultura e aos costumes locais. São inúmeros os exemplos que vão desde a criação de grandes projetos para a região às propostas de desenvolvimento com a, suposta, integração desta ao restante do país. Essas intervenções são alvo de críticas, pois não atendem às reais necessidades das populações locais, pelo contrário, tendem a reforçar o quadro de desigualdades sociais próprio da ordem burguesa, situação que nos remete às advertências de Marx (1996b) ao formular a explicitação da Lei Geral da Acumulação Capitalista no capítulo XXIII d'O Capital.

Acerca da presença e do avanço do capital na região, Teixeira (2008) sintetiza essa inquietação em duas passagens que nos remetem ao agravamento da questão socia/ ${ }^{9}$ para os sujeitos 
locais. Segundo a autora, a questão social estaria ligada à modernização conservadora empreendida nas localidades amazônicas orientação da qual compartilho o entendimento. A autora considera que:

A industrialização, encravada na Amazônia, não consegue mudar o caráter de atividade produtiva não-soberana para o país e não altera a condição da região como fonte de saque. Não produz os chamados efeitos "para a frente" e "para trás" da economia, inviabilizando valor agregado e geração de riqueza interna.

Houve um momento em que os Planos Nacionais de Desenvolvimento (PNDs) e Planos de Desenvolvimento da Amazônia (PDAs), com o apoio do Desenvolvimento de Comunidade, introduziam programas de "modernização conservadora", mas já embrionários da modernização destrutiva (MÉSZÁROS, 2003), ao dissolver relações não-capitalistas. Destrutiva tanto dos povoados amazônicos quanto dos ecossistemas: o Polamazônia ${ }^{10}$, a colonização dirigida, os incentivos fiscais, os grandes Projetos, o Programa Grande Carajás, a Hidroelétrica de Tucuruí, a Zona Franca de Manaus, entre outros. É quando a "questão social" começou, de fato, a assumir magnitude impensável e sem precedentes, nessa região que teria todas as condições para construir uma sociedade feliz. (TEIXEIRA, 2008, p. 147).

Nesse sentido, o avanço e a presença do capital na região amazônica são condicionadores dos processos de aniquilamento de ecossistemas e de relações sociais preexistentes em suas distintas localidades. Entende-se que nessa mesma região (unidade) coexistem processos diversos (diversidade) no que se refere tanto às relações sociais quanto aos ecossistemas e que estamos tratando de distintas faces amazônicas. Portanto, a Amazônia "[...] de certo modo [...] ainda resiste a uma homogeneidade produzida pelos atores hegemônicos da economia, da cultura e da política, os quais tendem a instituir a mesma e igual composição em todos os lugares" (TEIXEIRA, 1998, p. 99-100). Conquanto, a resistência frente à presença e ao avanço do capital na região mediante o surgimento de movimentos sociais organizados, conformando uma vontade política ${ }^{11}$ in lócus, os danos materiais (objetivos) e não materiais (subjetivos) não podem ser reparados por valor monetário algum, já que as qualidades inerentes ao ambiente esvaíram-se com o processo de extração mineral e seus efeitos estão impressos nas várias formas de vida locais.

É prudente destacar que a atenção aos efeitos da presença de mineradoras, nomeadamente tentáculos ou braços do capital na região, é recente, se tomamos como referência a produção acadêmica a esse respeito. Pode-se até afirmar que, ao considerarmos os processos de produção de conhecimento atinente à exploração mineral, sobretudo o polo relativo aos atingidos pela presença dessas empresas na região amazônica, tal produção somente passa a fazer parte dos diálogos em âmbito acadêmico (enquanto categoria) a partir do ano de 2010. A emergência da questão está relacionada:

[...] com o aparecimento do Movimento de Atingidos pela Vale, do Movimento dos Atingidos por Mineração (MAM), do Movimento Juventudes Atingidas por Mineração e do Comitê Nacional em Defesa dos Territórios Frente à Mineração. Até então, a noção de "atingidos" limitava-se aos atingidos por barragens, cujo debate se encontrava amplamente difundido a nível nacional e internacional na esfera política e acadêmica (VAINER, 2008 apud WANDERLEY, 2012, p. 58). 
Tais estudos revelaram o surgimento dessas organizações sociais com viés de mobilização coletiva, que ao dar conta de que há uma dimensão de resistência das comunidades locais frente à presença e ao avanço do capital na região amazônica, para além de mera produção acadêmica, deram maior visibilidade a essas questões. Trata-se de um processo predatório de exploração mineral com histórico de usurpação das terras que, sob o aval do Estado brasileiro, tem retirado daqueles que historicamente viveram e devem/deveriam ser reconhecidos como verdadeiros proprietários, 0 acesso pleno aos benefícios da produção mineral, restando-lhes as sequelas objetivas e subjetivas assinaladas anteriormente.

Esse movimento de exploração/expropriação inicia-se com o suposto propósito de "[...] valorização industrial de recursos minerais - entendida como a agregação de valor e conversão de recursos minerais em mercadoria - na Amazônia oriental brasileira [...]" (MONTEIRO, 2005, p. 187, grifos nossos).

Essa perspectiva de abordagem converge com o que:

Edna Castro, Sara Alonso e Sabrina Nascimento, no artigo "Mineração na PanAmazônia: neoextrativismo, colonialidade e lutas territoriais" (2016), [que] também abordam a inserção dos recursos da região amazônica no mercado mundial - desde a ditadura de 1964 - como central na produção de commodities. O neoextrativismo no contexto brasileiro, como nos demais países, está articulado a uma retomada de projetos de desenvolvimento e crescimento econômico, em que uma região rica em recursos naturais e energéticos é colocada como central para o planejamento do país através do estímulo de investimentos transnacionais (Coelho, M. C. N., 2016). (VINCENT; VASCONI, 2017, p. 68, grifos nossos).

Contudo, o neoextrativismo consolidado na região não visa 0 atendimento às necessidades fundamentais de grupos humanos nela presentes, muito pelo contrário, atendem a demandas e interesses externos, de que as empresas de mineração são uma das maiores expressões, sob os auspícios (parcial e/ou integral quando se trata dos efeitos deletérios do processo de exploração minero-metalúrgico) do Estado brasileiro. Como afirma Pinto (2018): "A internacionalização da Amazônia é um fato, [...] por seus efeitos negativos. Desde o período colonial, a região esteve mais ligada ao exterior do que ao Brasil, ao qual foi integrada tardiamente, a última das regiões incorporadas à nação, sem ser por ela compreendida". Esse legado é representado pelas desigualdades locais/regionais as quais se manifestam em várias dimensões, seja de ordem política, econômica, social, cultural, etc.

Iniciada na década de 1950, as primeiras explorações minerais na Amazônia sob o aval do Estado brasileiro, se deram na Serra do Navio, então Território Federal do Amapá. "Era o fim da ditadura de Getúlio Vargas e a nova Constituição, promulgada em 1946, em substituição à Carta de 1937, estava fortemente inspirada em princípios do liberalismo econômico" (MONTEIRO, 2005, p. 187). Reforça o autor: 
Para a valorização da jazida estabeleceu-se concorrência, que foi vencida pela Indústria e Comércio de Minérios S. A. (Icomi), uma empresa brasileira de médio porte. Em 1947, ela recebeu autorização do Governo Federal para pesquisar e para explorar o manganês. Em 1950, sob a alegação da necessidade de aporte técnico, de recursos financeiros e diante da inexistência de óbices constitucionais, a Icomi associou-se à Bethlehem Steel, naquele período a segunda maior corporação norte-americana produtora de aço (Chandler, 1998, p. 360), sendo, em 1957, efetivado o primeiro embarque de minério, atividade que se estendeu por quatro décadas (MONTEIRO, 2005, p. 187-138).

Desse movimento resultou o exaurimento da jazida no ano de 1997, restando os efeitos deletérios às comunidades, seus comunitários e ao município adjacente à Serra do Navio no Estado do Amapá, o município de Santana. Com a exploração por 40 anos, o que se constata atualmente é que "[...] Além de imensas pilhas de rejeitos e de finos, a Icomi deixou um passivo ambiental, com contaminação de rios e lençóis freáticos por arsênio 12". (VERBETES.CETEM, 2012, p. 1). São alguns dos efeitos nefastos e mais comuns em áreas/regiões onde o processo de exploração mineral se desenvolve. Em Serra do Navio e Santana:

0 arsênio contaminou a água da barragem e as águas do subsolo em suas imediações. Como na época das chuvas a barragem transbordava, os igarapés Elesbão I e II, usados pela população local para diversas finalidades, foram contaminados por arsênio, conforme constatação da Secretaria de Meio Ambiente do Amapá (Sema-AP) (PEREIRA et al., 2009; FIQUEIREDO; BORBA; ANGÉLICA, 2006). (VERBETES.CETEM, 2012, p. 2).

As questões afeitas à saúde dos munícipes são as mais frequentes, mas não únicas, e em alguns casos perceptíveis ao senso comum. Todavia, demandam estudos e pesquisas que em profundidade, com viés científico contra hegemônico, podem corroborar a apreensão sobre as reais condições ambientais, econômicas, sociais, sobretudo atinente à saúde e à habitação, dos moradores locais, condicionadas pelos efeitos da extração mineral enquanto ônus irreparável para a região e seus moradores.

Em trabalho realizado por Drumond (2000), fruto de sua tese de doutorado, encontramos uma análise consistente e louvável pelo levantamento de dados e mesmo pela análise realizada. Contudo, a abordagem suaviza os efeitos do processo de extração mineral, em que a ICOMI figura, em nosso entendimento, enquanto condicionante/determinante da atual situação desencadeada pelos investimentos privados com impactos que se refletem na qualidade de vida na localidade. A conclusão de Drumond (2000, p. 789) pode ser expressada no seguinte fragmento:

Em suma, constatei que, depois de cinquenta anos de prospecção, mineração, processamento, transporte e embarque de milhões de toneladas de minério de manganês no Amapá, a Icomi não causou destruição ambiental maciça e não causou estagnação ou disrupção socioeconômica, mesmo que o Amapá não tenha alcançado um status de estado desenvolvido, questão importante, mas distinta.

A abordagem realizada por Drumond (2000) destoa de outras empreendidas por estudiosos e/ou pesquisadores na região. Ademais, somos do entendimento de que os danos produzidos pela extração mineral, pois envolve o uso de determinados componentes químicos e 
processos químico-físicos, são irreparáveis ainda que se empreendam diversas formas de mitigar os efeitos segundo o pretenso Desenvolvimento Sustentável. Sinteticamente, pode-se afirmar que o processo de exploração mineral na região representa, quantiqualitativamente, um ônus para as populações locais. Sob tal detrimento se plasma a base dos bônus advindos da exploração das riquezas amazônicas por meio das empresas de mineração ao ampliarem sua rentabilidade econômica até o limite, como no caso de Serra do Navio, expressão desse movimento.

Em reportagem do jornal Brasil Repórter, publicada em 01 de janeiro de 2001, Sakamoto (2001) nos apresenta um outro panorama, portanto, divergente das ponderações de Drumond (2000). Sakamoto (2001, p. 1) afirma que "A Indústria e Comércio de Minérios S.A. (Icomi) [estava] sendo acusada pelo governo do estado do Amapá de ter contaminado a região do porto de Santana, próximo da capital Macapá, com arsênio - substância altamente tóxica que pode provocar câncer e até a morte". Ainda segundo o autor:

[...] Processos para o enriquecimento do manganês, proveniente da Serra do Navio, teriam liberado 0 produto, impregnando 0 ar e a água. Perto dali, a vila do Elesbão, uma comunidade de pescadores que vive sobre palafitas às margens do rio Amazonas, enfrenta graves problemas de saúde.

De acordo com a Secretaria do Meio Ambiente do Amapá (Sema), exames preliminares feitos pela Universidade Federal do Pará, a partir de amostras de cabelo de cem moradores da vila do Elesbão, indicaram que 98 teriam no organismo índice de arsênio superior ao tolerado pela Organização Mundial da Saúde.

O governo do estado, através da Sema, já aplicou duas multas: uma no valor de $\mathrm{R} \$ 40$ milhões, pela contaminação, e outra de $R \$ 12$ milhões, por ter a empresa levado de volta 0 minério contaminado às minas da Serra do Navio. A Icomi recorreu na Justiça. José Luiz Ortiz Vergolino, diretor superintendente da empresa, diz que estão sendo aguardados resultados de novas análises na população da vila, e que já foi determinada a transferência do minério para um aterro controlado.

A pesquisa e o laudo estão a cargo do Instituto Evandro Chagas, ligado à Fundação Nacional da Saúde, em Belém. Porém, de acordo com Edvaldo Souza, assessor jurídico da Sema, independentemente do resultado desses exames, o governo dará continuidade ao processo na Justiça, devido à enorme quantidade de provas e evidências que mostram a negligência da empresa no caso.

Enquanto isso, o Elesbão aguarda. "Estão morrendo crianças e os próprios adultos. Mas ninguém vem informar a gente de nada. A população continua nadando no rio e comendo camarão", reclama Josequias Antônio da Silva, líder comunitário da vila. (SAKAMOTO, 2001, p. 1, grifos do autor).

As fendas abertas na floresta (Figura 1) atestam o quão grande é o impacto dessas atividades realizadas na região. Esse dado concreto não pode ser anulado da vida das populações presentes na região amazônica e que vivenciam cotidianamente as consequências negativas do processo predatório de aniquilamento das riquezas naturais e humanas, como já nos advertiu Antunes (2001) citando Mészáros.

A contaminação produzida pela mineração, a exemplo do que ocorreu na Serra do Navio no Amapá, não pode impedir que as pessoas continuem fazendo uso da natureza para atender suas necessidades humanas fundamentais como sempre fizeram, já que estas são herdeiras de uma 
sociabilidade, que como já dissemos em outro momento, não se enquadram na lógica de mercado própria da sociabilidade burguesa que tende as subsumir. A fala do senhor Josequias Antônio da Silva, líder comunitário da vila, exprime essa dimensão quando o mesmo afirma que "A população continua nadando no rio e comendo camarão" (SAKAMOTO, 2001, p. 1) sem que the seja dado a conhecer a vulnerabilidade a que está submetida.

Como se pode ver, a compensação aos efeitos derivados da extração mineral, como os ora mencionados, que deveria se desenvolver numa perspectiva de atender aos protocolos (nacionais e internacionais) que regulamentam a exploração do minério no Brasil, não tem conseguido traduzir-se na prática ${ }^{13}$. Revela-se, assim, o engodo do discurso da sustentabilidade social, econômica e ambiental, como pode ser constatado na "[...] comunidade de pescadores que vive sobre palafitas às margens do rio Amazonas, [e] enfrenta graves problemas de saúde [...] resultado da 'Triste herança' da Icomi na região", conforme Sakamoto (2001, p. 1).

\section{Figura 1 - 0 bloco de manganês que aflorava à superfície ficava acima da cratera aberta pela exploração}

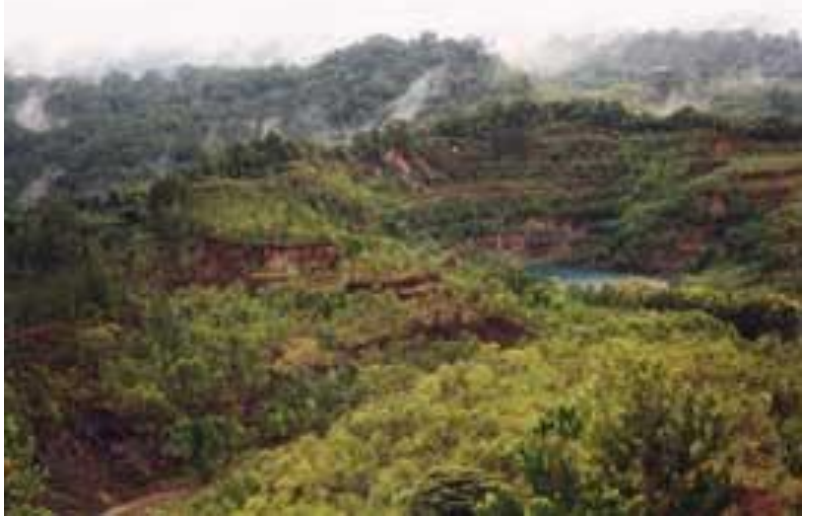

Fonte: SAKAMOTO, L. Triste herança. Repórter Brasil, São Paulo, 2001. Disponível em: http://www.reporterbrasil.com.br/exibe. Acesso em: 23 jul. 2018.

Outros aspectos como os de ordem simbólica-cultural ${ }^{14}$ ocupam um lugar importante, além dos que dizem respeito às noções de territorialidade que envolvem a desapropriação e/ou expropriação, por exemplo, e que incidem na produção do quadro de desigualdades a que nos referimos anteriormente.

Os problemas socioambientais relacionados aos rejeitos advindos das atividades de pelotização ${ }^{15}$, no caso de Serra do Navio do minério manganês, e outros oriundos da exploração mineral das demais localidades da região têm sido uma constante e objeto de denúncias por parte das populações amazônidas. No início de 2018, por exemplo, houve a denúncia de que:

Áreas no Nordeste do Pará foram contaminadas pelo vazamento de rejeitos de bauxita da barragem da mineradora norueguesa Hydro Alunorte, segundo laudo divulgado nesta quintafeira pelo Instituto Evandro Chagas, em Belém. O relatório aponta que houve contaminação 
ambiental em três comunidades do município de Bacarena, que fica a 15 quilômetros de Belém. Em nota, a empresa disse que irá analisar o laudo para se pronunciar (O GLOBO, 2018, grifos do original).

Dessas problemáticas, reitera-se que o ônus das atividades minerárias na região recaem sobre os sujeitos locais e os benefícios exponenciais, em forma de rentabilidade econômica e suas consequências positivas, atendem a outras necessidades que não as dos amazônidas. Atendem à contínua acumulação própria à ordem burguesa apreendida na Lei Geral da Acumulação Capitalista conforme os pressupostos marxianos.

Vimos anteriormente a diversidade que se expressa nas várias formatações das populações contemporâneas da Amazônia (FREITAS, 2009; TEIXEIRA, 1998, 2008). Dentre essas, estão as comunidades remanescentes de quilombo. Uma em particular, a Comunidade de Boa Vista ${ }^{16}$ do Rio Trombetas no Estado do Pará e as demais comunidades que conformam a Associação dos Remanescentes de Quilombo do Município de Oriximiná (ARQMO) ${ }^{17}$. Por suas características, essas comunidades lidaram com os efeitos da presença de mineradoras, levando-as a demarcar o seu espaço físico, político, cultural, social e econômico, que ainda hoje refletem a existência de problemas os mais diversos advindos com a presença da mineradora na localidade.

De acordo com Archanjo (2015, p. 34-35):

Essas comunidades [...] vivenciaram de maneira intensa e conflituosa a implantação dos grandes projetos na Região Amazônica. Boa Vista, entre todas, foi a que sofreu maior impacto, quando da chegada do Projeto Trombetas, a criação da Reserva Biológica e a Floresta Nacional Saracá-Taquera representaram para comunidade o cercamento e a expropriação de seu território de caça, pesca e atividade extrativista, inviabilizando a reprodução por meio próprio de todo um modo de vida.

Os remanescentes de quilombos do rio Trombetas lutam, diariamente, na defesa de seus direitos: a terra, liberdade social e igualdade econômica. À medida que seu território estava sendo expropriado pelo grande capital e pelo próprio Estado brasileiro sentiram-se ameaçados, cercados, encurralados em suas terras de moradia, perdendo seu espaço de trabalho, lazer e de lembranças, enfim, perderam sua segurança e garantia de sobrevivência.

Em outra localidade, na mesma região onde se desenvolveram os conflitos em decorrência da presença da exploração mineraria, encontramos a Região de Juruti Velho, onde se instalou a ALCOA - Aluminum Company of America ${ }^{18}$. Nessa região constatamos o surgimento da Associação das Comunidades da Região da Gleba Juruti Velho (ACORJUVE) ${ }^{19}$. Por sua vez, essa associação pautou sua luta em defesa do território coletivo, superando divergências entre os membros, tendo como fim a titulação do assentamento agroextrativista e a implementação de outras políticas públicas combatendo o descaso público e o ardil da empresa minerária. Essa iniciativa não se deu sem problemas. Ainda assim, revelou a face predatória do processo de extração mineral e seus objetivos últimos, além de denunciar os prejuízos deixados pela mineradora durante todo o processo de implantação e implementação do projeto. Essas denúncias vão ao encontro do que Zhouri $(2018$, p. 11) 
advogam, pois referem-se às questões que perpassam "Às violências materiais e simbólicas, intrínsecas à expansão das fronteiras minerárias, [que] somam-se as violências epistêmica [...]"

Um recorte reflexivo acerca de outra região minerária, também no estado do Pará, situada na conhecida Região Sudeste do Estado e que é parte do Programa Grande Carajás (PGC), nos é apresentado por Palheta e outros (2017). O PGC fora criado dada a necessidade de agilizar "[...] a instalação e a operação dos projetos mínero-metalúrgicos" (MONTEIRO, 2005, 190) na região amazônica. "Uma tentativa de coordenar a execução de projetos já existentes na área (especialmente o Projeto Ferro Carajás, a Albras, a Alunorte, a Alumar [Maranhão] e a Usina de Tucuruí) e de concentrar ainda mais os recursos estatais e os oriundos de incentivos fiscais e creditícios." (MONTEIRO, 2005, 190).

Palheta e outros (2017) detiveram atenção especial em suas análises para a denominada Região de Carajás. A razão está no fato de que nessa região: "[...] estão concentrados os maiores projetos de mineração da companhia Vale [do Rio Doce] na região Sudeste paraense [...]" verticalizam para "[...] a província mineral de Carajás, para verificar "os efeitos das atividades mineradoras" "[...] nos municípios Parauapebas, Canaã dos Carajás, Marabá, Ourilândia do Norte, São Felix do Xingu e Curionópolis, que concentram os maiores projetos da Vale [...] principalmente, a partir da primeira metade do século XXI." (PALHETA et al., 2017, p. 2).

Os autores, citando Villa Verde, Alamino e Fernandes fazem a seguinte conclusão:

Essas populações sofrem, principalmente, com os problemas provenientes do modo com os quais os empreendimentos do setor mineral são implantados, ainda aquém do papel inclusivo que poderiam melhor assumir. Daí emerge o crescimento desordenado, o inchaço populacional, a infraestrutura inadequada, empobrecimento, etc. (PALHETA et al, 2017, p. 5).

Todavia, ainda que considerem a possibilidade do papel inclusivo dos empreendimentos minerários, suas análises tendem a denunciar as contradições engendradas pela modalidade de extração mineral característica na região amazônica. Não há como pensar quaisquer formas de inclusão quando se considera a forma de ser capitalista e a forma de ser das empresas de mineração na região na qualidade de tentáculos do capital cujo fim último é a rentabilidade econômica, a acumulação, além do atendimento de necessidades alheias às populações locais, relegando-as a um quadro crescente de desigualdades.

A contra-hegemonia frente a essas questões pode ser amparada em Teixeira (1998). A autora, após, participação em uma audiência pública que tratava, à época, da privatização da Vale do Rio Doce, fez a seguinte síntese. Vejamos:

O dr. Bautista Vidal, num seminário que tivemos em defesa da Vale do rio Doce, elencou algumas das dependências do dito Primeiro Mundo de produtos absolutamente estratégicos para o terceiro milênio: os EUA, o Japão e a União Europeia dependem cem por cento do nióbio, do qual só o Brasil detém $99 \%$ das reservas do planeta. Os EUA dependem do 
manganês (que está na Amazônia) 98\%, a União Europeia 100\% e o Japão 100\%. Do alumínio, que também está na Amazônia, o Japão depende 100\%, a União Europeia 99\% e os EUA $91 \%$, o que nos leva a interrogar: quem realmente é dependente? (TEIXEIRA, 1998, p. 99, grifos da autora).

Dessa assertiva, parece-nos inadmissível que diante de tamanha constatação, e tendo a Amazônia como uma fonte finita de riqueza, os sujeitos amazônidas encontrem-se reféns da forma predatória desencadeada pelo processo de exploração mineral na região que, sob o aval do Estado brasileiro, Ihes tem legado o ônus desse movimento deletério.

O histórico processo de extração mineral, que atualmente na condição de commodittes (mercadorias) as quais representam, na sua totalidade, parte importante da produção nacional, 6,8\% do PIB brasileiro o que equivale a $65 \%$ do valor das exportações brasileiras, mostra-se como um dos determinantes das desigualdades engendradas na região.

Como nos alertou Marx (1996a, p. 165):

Cada coisa útil, como ferro, papel etc., deve ser encarada sob duplo ponto de vista, segundo qualidade e quantidade. Cada uma dessas coisas é um todo de muitas propriedades e pode, portanto, ser útil, sob diversos aspectos. Descobrir esses diversos aspectos e, portanto, os múltiplos modos de usar as coisas é um ato histórico. Assim como também o é a descoberta de medidas sociais para a quantidade das coisas úteis. A diversidade das medidas de mercadorias origina-se em parte da natureza diversa dos objetos a serem medidos, em parte de convenção.

Ao situarmos as commodittes de minério retiradas da região amazônica na perspectiva desenvolvida por Marx (1996a), nos permite extrair uma convenção contraposta ao valor atribuído a essas mercadorias no atual estágio de desenvolvimento do capital na Amazônia que tem convertido os sujeitos locais em apêndices do mercado (POLANYI, 2000). É preciso redescobrir esses diversos aspectos que conformam a mercadoria minério, pois "[...] os múltiplos modos de usar as coisas é um ato histórico." (MARX, 1996a, p. 165). É possível, portanto, à luz dessa perspectiva, ressignificar o modo como vem se realizando o processo de extração mineral na região, pois consideramos que nos amazônidas tem recaído o ônus da forma predatória de se produzir riqueza pelas empresas minerárias, as quais potencializam a agudização das desigualdades em suas muitas dimensões. Na verdade, tratase de um ato histórico, portanto, passível de mudança e/ou transformação.

\section{CONCLUSÃO}

Refletir sobre o papel das commodittes de minério no atual estágio de desenvolvimento do capitalismo na região amazônica, em que as empresas minerárias apresentam-se como expressão da presença e avanço do capital na região, é sine qua non para compreendermos os quadros de desigualdades engendrados na região. 
À luz da teoria social de Marx, em que a mercadoria e a Lei Geral da Acumulação Capitalista têm um lugar de destaque para essa apreensão, percebemos que a realidade produzida por esse processo de expropriação da riqueza revela um campo de expressões que engrossam o quadro de desigualdades in lócus. A utilidade amazônica, e aqui precisamente, os minérios extraídos em larga escala, revela-se como produto voltado ao atendimento de necessidades alheias às populações locais, pois se voltam precipuamente para a rentabilidade inerente ao modus operandi do capital.

Neste estudo destacamos que a presença dessas empresas na região conforma um quadro de exploração da riqueza oriunda da natureza de modo que os ganhos reais se voltam para atender à rentabilidade capitalista em detrimento das condições e modos de vida dos sujeitos históricos presentes na região para os quais sobram as consequências deletérias da forma de ser do capital e o acirramento das desigualdades, a nível local, em suas muitas dimensões.

\section{REFERÊNCIAS}

ANTUNES, R. Trabalho e precarização numa ordem neoliberal. In GENTILI, P.; FRIGOTTO, G. (orgs). A cidadania negada: políticas de exclusão na educação e no trabalho. São Paulo: Cortez, 2001. p. 3548.

ARCHANJO, E. C. O. F. Oriximiná terra de negros: trabalho, cultura e luta de quilombolas em Boa Vista (1980-2013). 2015. Dissertação (Mestrado em história) - Programa de Pós-graduação em História, Instituto de Ciências Humanas e Letras, Universidade Federal do Amazonas, 2015.

BARREIRA, C. Crônica de um massacre anunciado: Eldorado dos Carajás. São Paulo em Perspectiva, São Paulo, v. 13, n. 4, p. 136-143, 1999.

BRASIL. Ministério da Integração Nacional. Superintendência do Desenvolvimento da Amazônia SUDAM. Legislação da Amazônia. Brasilia, DF, [20--?]. Disponível em http://www.sudam.gov.br/index.php/prda/58-acesso-a-informacao/86-legislacao-da-amazonia. Acesso em: 5 abr. 2018.

CASTRO, J. R. As commodities e seu impacto na economia do Brasil. Nexo, [S. I.], 2016. Disponível em: https://www.nexojornal.com.br/explicado. Acesso em: 3 mai. 2018.

DRUMOND, J. A. Investimentos privados, impactos ambientais e qualidade de vida num empreendimento mineral amazônico - 0 caso da mina de manganês de Serra do Navio (Amapá). História, Ciências Saúde - Manguinhos, Rio de Janeiro, v. 6, suppl., p. 753-792, 2000.

FREITAS, M. C. da S. Os amazônidas contam a sua história: territórios, povos, populações. In SCHERER, E.; OLIVEIRA, J. A. de (Orgs.). Amazônia: territórios, povos tradicionais e ambiente. Manaus: Editora da Universidade Federal do Amazonas, 2009.

HAURADOU, G. R.; AMARAL, M. B. Sujeitos coletivos e vontade coletiva na Amazônia: uma aproximação do pensamento de Gramsci. Brazilian Applied Science Review, São José dos Pinhais, PR, v. 2, n. 3, p. 1075-1086, 2018 
LESSA, S. Bayond Capital: Estado e Capital. Serviço Social e Sociedade, São Paulo, ano XIX, n. 56, p. 135-151, 1998.

MARX, K. O Capital: crítica da economia política. São Paulo: Nova Cultural Ltda, 1996b. Livro 1, t. 2.

MARX, K. O Capital: crítica da economia política. São Paulo: Nova Cultural Ltda, 1996a. Livro 1, t. 1.

MONTEIRO, M. de A. Meio século de mineração industrial na Amazônia e suas implicações para o desenvolvimento regional. Estudos Avançados, São Paulo, v. 19, n. 53, p. 187-207, 2005. Disponível em: www.scielo.br/scielo.php?script=sci_arttext\&pid=S0103-40142005000100012. Acesso em: 4 ago. 2018.

MOURÃO, J. M. Aspectos conceituais relativos à pelotização de minérios de ferro. Vitória: [s. n.], 2017. Disponível em: file:///C:/Users/pc/Downloads/aspectos-conceituais-relativos-a-pelotizacao-deminerio-de-ferro.pdf. Acesso em: 5 ago. 2018.

O GLOBO. Laudo confirma vazamento de rejeitos de mineradora no Pará. [S. I.], 2018. Disponível em: http://m.oglobo.globo.com. Acesso em: 25 jul. 2018.

PALHETA, J. M. et al. Conflitos pelo uso do território na Amazônia mineral. Mercator, Fortaleza, v. 16, e16023, p. 1-18, 2017. Disponível em: www.mercator.ufc.br. Acesso em: 17 jul. 2018

PAULO NETTO, J. (org.) O leitor de Marx. Rio de Janeiro: Civilização Brasileira, 2012.

PINTO, L. F. A utopia amazônida. Amazônia Real, [S. I.], 2018. Disponível em:

http://amazoniareal.com.br/a-utopia-amazonida/. Acesso em: 4 ago. 2018.

POLANYI, K. A grande transformação. Rio de Janeiro: Elsevier, 2000.

PORTAL AMAZÔNIA. Um ano depois, massacre de Pau D'arco, no Pará, tem 13 indiciados. Manaus, 2018. Disponível em: http://portalamazonia.com/noticias/um-ano-depois-massacre-de-paudarco-no-para-tem-13-indiciados. Acesso em: 27 mai. 2018.

RANCIARO, M. M. M. de A. Formação histórica e tradições socioculturais vivenciadas em povoados rurais amazônicos. In CHAVES, M. do P. S. R.; SANTIAGO, J. L. Inovação, Desenvolvimento e Sustentabilidade na Amazônia. Manaus: EDUA, 2014.

SAKAMOTO, L. Triste herança. Repórter Brasil, São Paulo, 2001. Disponível em:

http://www.reporterbrasil.com.br/exibe. Acesso em: 23 jul. 2018.

TEIXEIRA, J. B. A assistência social na Amazônia. Serviço Social e Sociedade, ano XIX, n. 56, 1998.

TEIXEIRA, J. B. Meio Ambiente, Amazônia e Serviço Social. Em Pauta, Rio de Janeiro, n. 21, p. 141$152,2008$.

TULIO NETO, P. de. Soberania e ingerência na Amazônia brasileira. Rio de Janeiro: Centro

Edelstein de Pesquisa Social, 2010. Disponível em: http://books.scielo.org. Acesso em: 2 jun. 2018. 
VERBETES.CETEM. Mineração de manganês deixa passivo socioambiental em Serra do Navio (AP). Rio de Janeiro: CETEM, 2012. Disponível em: www.verbetes.cetem.gov.br. Acesso em: 18 jul. 2018.

VINCENT, H. D.; VASCONI, M. C. M. Mineração na América do Sul - Neoextrativismo e Lutas Territoriais (2016). Interfaces - Revista de Extensão da UFMG, Belo Horizonte, v. 5, n. 2, p. 66-76, 2017. Disponivel em: https://www.ufmg.br/proex/revistainterfaces/index.php/IREXT/article/.../311/pdf. Acesso em: 30 jun. 2018.

WANDERLEY, L. J. Movimentos sociais em área de mineração na Amazônia brasileira. E-cadernos CES, Coimbra, n. 17, p. 56-84, 2012.

ZHOURI, A. (org.). Mineração, violências e resistências: um campo aberto à produção de conhecimento no Brasil. 1. ed. Marabá, PA : Editorial iGuana; ABA, 2018. Disponível em: http://www.uff.br/poemas/files/2016/06/Santos-Milanez-2018-A-Constru\%C3\%A7\%C3\%A3o-doDesastre-e-a-Privatiza\%C3\%A7\%C3\%A30-da-Regula\%C3\%A7\%C3\%A3o-Mineral-com-capa.pdf. Acesso em: 1 jun. 2018.

ZHOURI, A.; BOLADOS, P.; CASTRO, E. (orgs). Mineração na América do Sul: neoextrativismo e lutas territoriais. 1. ed. São Paulo: Annablume, 2016. (Coleção Cidadania e Meio Ambiente).

\section{Notas}

1 Um retrato dessa questão é o fato de que: "As forças policiais e privadas aparecem conjuntamente nas soluções de conflitos agrários. A Conferência Nacional dos Bispos do Brasil - CNBB, em 1980, fez a seguinte declaração: 'Em quase todas as unidades da Federação, sob formas distintas, surgem conflitos entre, de um lado, grandes empresas nacionais $e$ multinacionais, grileiros e fazendeiros e, de outro, posseiros e índios. Violências de toda a ordem se cometem contra esses últimos para expulsá-los da terra. Nessas violências, já se comprovou amplamente, estão envolvidos desde jagunços e pistoleiros profissionais, até forças policiais, oficiais de Justiça e juízes. Não raro observa-se a anomalia gravíssima de composição de forças de jagunços e policiais para executar sentenças de despejo'. As denúncias são intermináveis, aparecendo em cena os grandes proprietários, juízes, pistoleiros e policiais" (BARREIRA, 1999, p. 139, grifos do autor).

2 "[...] grave conflito que ocorreu entre as forças de segurança do Estado do Pará Polícia Militar) e trabalhadores rurais. 0 campo brasileiro é novamente palco de um cenário importante ocorrido no dia 17 de abril de 1996, quando o governador do Pará 'mandou a polícia militar desocupar uma estrada no sul do seu Estado. Saldo da operação de trânsito rodoviário: uma carnificina com duas dezenas de sem-terra mortos e 51 feridos. Os homens e as mulheres atacados na floresta, que deixaram sangue e pedaços de cérebro espalhados pelo chão e pela relva, são esses brasileiros chamados de sem-terra, cidadãos que andam descalços, têm roupas sujas de barro e só costumam ser notícia na forma e cadáver' (Veja, 24/04/96). Este acontecimento, nomeado como o 'massacre de Eldorado dos Carajás'” [...] (BARREIRA, 1999, p. 137, grifos do autor).

3 “[...] massacre que vitimou dez trabalhadores rurais em Pau D'Arco, no município de Redenção, sudeste do Pará [...]. 0 crime aconteceu na madrugada do dia 24 de maio de 2017. Dezenove policiais foram investigados pelas mortes, 13 deles, indiciados e atualmente estão presos, mas os mandantes da chacina não chegaram a ser identificados (PORTAL AMAZÔNIA, 2018; grifos do autor)".

3 "A palavra inglesa 'commodity' significa simplesmente mercadoria. Mas no mercado o termo se refere a produto básico, em estado bruto ou com baixo grau de transformação. São mercadorias com pouco valor agregado e quase sem diferenciação - que podem portanto ser negociadas globalmente sob uma mesma categoria. Minério de ferro, madeira, carne e frango 'in natura' e petróleo são algumas das mais comercializadas" (CASTRO, 2016, p. 1).

4 "A palavra inglesa 'commodity' significa simplesmente mercadoria. Mas no mercado o termo se refere a produto básico, em estado bruto ou com baixo grau de transformação. São mercadorias com pouco valor agregado e quase sem 
diferenciação - que podem portanto ser negociadas globalmente sob uma mesma categoria. Minério de ferro, madeira, carne e frango 'in natura' e petróleo são algumas das mais comercializadas" (CASTRO, 2016, p. 1).

${ }^{5}$ Este desprezar refere-se ao não reconhecimento efetivo dos reais senhores e senhoras das terras, dos ecossistemas, das vidas amazônicas contemporâneas. Pois, parte dos afetados pela presença de agentes exógenos à região não dispõem de organizações coletivas (associação, sindicato, etc.) que deem conta de atender suas necessidades dado 0 caráter multifacetado das populações da região. "As populações contemporâneas da Amazônia são compostas de grupos sociais urbanos e rurais heterogêneos do ponto de vista da situação econômica; de sociedades e comunidades indígenas de distintos e diversos modos de adaptação e articulação histórico-cultural; de grupos isolados remanescentes de friç̧ão interétnicas e de arranjos próprios de sobrevivência com a sociedade nacional; e, ainda, de grupos e contingentes populacionais deslocados para a região por mecanismos governamentais, privados e confessionais e por migrações internas e externas, independentes ou promovidas por fluxos de exploração econômica ou reajustes institucionais na Amazônia." (FREITAS, 2009, p. 23-24).

6 Uma coletânea com quinze artigos foi organizada recentemente por Andréa Zhouri, Paola Bolados e Edna Castro (2016), intitulada Mineração na América do Sul: neoextrativismo e lutas territoriais, como resultado do I Seminário Internacional de mesmo nome, que ocorreu em agosto de 2015 na Universidade Federal de Minas Gerais, reúne produções de diversos autores e autoras que pensam criticamente o extrativismo nos países da América do Sul.

${ }^{7}$ De acordo com a Superintendência do Desenvolvimento da Amazônia (SUDAM), os estados que compõem a Amazônia Legal são: Acre, Amapá, Amazonas, Mato Grosso, Pará, Rondônia, Roraima, Tocantins e parte do Maranhão (oeste do meridiano de $44^{\circ}$ ). A Amazônia Ocidental é constituída pela área abrangida pelos estados do Amazonas, Acre, Rondônia e Roraima. Já os estados que compõem a Amazônia Oriental são: Pará, Maranhão, Amapá, Tocantins e Mato Grosso. Essa formatação decorreu do dispositivo legal (Lei no 1.806, de 6 de janeiro de 1953) onde a Amazônia Brasileira passou a ser chamada de Amazônia Legal, fruto de um conceito político e não de um imperativo geográfico. Foi a necessidade do governo de planejar e promover o desenvolvimento da região. Em 1966, pela Lei n 5.173, de 27 de outubro de 1966 (extinção da SPVEA e criação da SUDAM) o conceito de Amazônia Legal é reinventado para fins de planejamento. Assim, pelo artigo $45^{\circ}$ da Lei complementar no 31, de 11 de outubro de 1977, a Amazônia Legal tem seus limites ainda mais estendidos (BRASIL, [20--?]).

${ }^{8}$ Recentemente, em agosto de 2017, com a intenção de dar início à exploração mineral em uma área entre os estados do Pará e do Amapá, o governo federal publicou um decreto para a extinção da Reserva Nacional de Cobre e seus Associados (RENCA). Trata-se de uma área de $46.000 \mathrm{~km} 2$, criada em 1984, e que abriga em seu interior um total de nove áreas protegidas: duas Terras Indígenas e sete Unidades de Conservação, sendo três de proteção integral e quatro de uso sustentável. Alguns meses antes, uma portaria do Ministério de Minas e Energia procurou regulamentar as outorgas e os títulos minerais vigentes naquela área.5 Essas iniciativas fazem parte de um contexto mais amplo para reaquecimento do setor minero-extrativo, que conta ainda com o lançamento do Programa de Revitalização Mineral Brasileira em julho de 2017 e três Medidas Provisórias (MPs nº 789, 790 e 791) que versam sobre a criação da Agência Nacional de Mineração (ANM), a modificação do Código de Mineração e a revisão da legislação que trata da Compensação Financeira pela Exploração de Recursos Minerais (CFEM). "[...] Isso ocorre não somente no Brasil, mas na América latina como um todo. Na Colômbia, mudanças na legislação ambiental têm originado as 'licencias expressas', assim como as 'Paquetes ambientais no Peru, enquanto na Bolívia, novos decretos têm permitido a entrada de petroleiras em áreas protegidas." (ZHOURI, 2018, p. 16- 17).

${ }^{9}$ No âmbito do Serviço Social brasileiro há como certo o entendimento de que a questão social relaciona-se à emergência e desenvolvimento do Modo de Produção Capitalista cujas sequelas (expressões da questão social como o pauperismo, as inúmeras formas de violência, etc.) são fruto da apropriação da riqueza produzida pelos trabalhadores, mas que é apropriada por uma pequena parcela dessa mesma sociedade destituindo os trabalhadores do objeto da produção. Em síntese, trata-se das consequências da contradição capital X trabalho.

10 Programa de Polos Agropecuários e Agrominerais da Amazônia. "Para agilizar a implantação de projetos exportadores, 0 Governo Federal criou, em 1974, o Programa de Pólos Agropecuários e Agrominerais da Amazônia - Polamazônia. Os planos federais previam a implantação de diversos 'pólos de desenvolvimento na Amazônia brasileira', com destaque para a produção mineral. [...] Alguns dos pólos que integravam o Polamazônia eram Carajás, Trombetas e Amapá." (MONTEIRO, 2005, p. 188, grifos do autor).

11 Noutro lugar destacamos que, "[...] o surgimento de diversos segmentos como os supramencionados revela o traço distintivo de resistência das comunidades locais ante o avanço do capital na região amazônica. A conformação desses 
quadros reflete o posicionamento político gestado no cotidiano da vida das populações afetadas pelos 'projetos de desenvolvimento' em voga na região." (HAURADOU; AMARAL, 2018, p. 1080). "[...] Consideramos que a constituição dessas duas associações configurar-se-iam como expressão da vontade coletiva dos sujeitos coletivos amazônidas em favor do bem comum, com as devidas ressalvas." (HAURADOU; AMARAL, 2018, p. 1083).

12 “[...] Em Santana [município próximo à Serra do Navio], município com $1580 \mathrm{~km}^{2}$ e 101.203 habitantes (IBGE, 2010b), a população, em especial os moradores da Vila do Elesbão, ainda sofrem com os efeitos da contaminação por arsênio. A intoxicação causa distúrbios gástricos, intestinais, renais, problemas no sistema nervoso central, dentre outros. Os rejeitos abandonados em Santana são perigosos porque a estrutura do manganês foi alterada pelas altas temperaturas do processo de pelotização, que elimina o minério de baixo teor (CASARA, 2003)." (VERBETES.CETEM, 2012, p. 1).

13 Dentre esses protocolos está a realização do Estudo de Impacto Ambiental (EIA) e do Relatório de Impacto Ambiental (RIA) para fins de emissão de licenças ambientais e para a aprovação do Plano Técnico de Mina no processo da exploração mineral. Além de uma série de procedimentos que envolve audiências públicas com os comunitários que potencialmente serão afetados pela atividade minerária; de outros dispositivos que deveriam respaldar a possibilidade de mitigação dos efeitos ou impactos da presença de mineradoras nas localidades amazônicas e demais regiões do país ainda que estas já não estivem produzindo.

${ }^{14}$ No campo da Antropologia essa questão toma corpo, e no campo dos direitos humanos, mais ainda. Zhouri (2018, p. 11) destacam que: "Às violências materiais e simbólicas, intrínsecas à expansão das fronteiras minerárias, somam-se as violências epistêmica (Rigotto, Zhouri et al., neste volume), racial e de gênero. Imbricadas, elas constituem uma configuração típica daquilo que Quijano (2005) e Mignolo (2003) denominaram por colonialidade do poder e do saber".

15 Conforme Mourão (2017, p. 12) "Os minérios pobres têm de ser moídos e concentrados, gerando quantidades expressivas de finos abaixo de $0,15 \mathrm{~mm}$, próprios para a pelotização. No Brasil, essa atividade é bem desenvolvida, prevalecendo 0 uso da tecnologia Traveling Grate. 0 processo de pelotização foi desenvolvido para 0 aproveitamento desses minérios concentrados, ultrafinos, impróprios para 0 uso direto nos fornos siderúrgicos de produção de ferro primário, tais como: alto-forno, reator de redução direta, Corex, etc. A pelotização consiste na aglomeração desses finos, transformando-os em esferas de diâmetro médio da ordem de $12 \mathrm{~mm}$, com propriedades químicas, físicas e metalúrgicas adequadas para uso na Siderurgia [...]".

${ }^{16}$ Conforme Archanjo (2015, p. 22): "A comunidade quilombola de Boa Vista está localizada em região de várzea, na margem direta do rio Trombetas, fazendo fronteira, ao norte, com o rio Trombetas e enseada do Caripé, Bom Princípio e Patauá; a leste, com o igarapé de Água Fria e a floresta Nacional Saracá-Taquera; a oeste, com o igarapé de Patauá; ao sul, com o Igarapé Água Fria e a Floresta Nacional Saracá-Taquera. Observamos, ainda, outros limites não especificados no título de reconhecimento: no limite norte, está a Reserva Biológica do Trombetas e, no limite sul, a Mineração Rio do Norte"

17 Fundada "[...] em 1989, a ARQMO tinha como intuito fortalecer politicamente as comunidades negras na defesa dos direitos sociais e territoriais contra os interesses de outros atores, que se impuseram no planejamento territorial da bacia do Trombetas sobre as terras dos quilombolas. Constituiu também uma resposta aos impactos e às transformações decorrentes das políticas públicas e privadas de desenvolvimento regional, desde a década de 1970, com destaque para os projetos de mineração" (WANDERLEY, 2012, p. 63).

18 Dados oriundos dos estudos de Wanderley $(2012$, p. 58) que analisou os movimentos sociais que emergiram "[...] no município de Oriximiná, onde a empresa de capital misto Mineração Rio do Norte atua desde 1974; [e a] segunda área [...] localizada em Juruti, onde a transnacional ALCOA - Aluminum Company of America iniciou o seu empreendimento em 2000 e a extração em 2008. Ambas as localidades encontram-se na sub-região Baixo Amazonas, estado do Pará, na Amazônia Oriental".

19 "Em março de 2004, [após] uma assembleia com mais de dois mil associados e unindo quarenta comunidades [...] a ACORJUVE. A nova associação significou a união de todas as comunidades do lago Juruti Velho em defesa do território coletivo. Se, no princípio, ela não existia por unanimidade - especialmente nas comunidades evangélicas - hoje, com o fortalecimento político da instituição, a titulação do assentamento agroextrativista e a implementação de outras políticas públicas, quase a totalidade dos moradores e todas as comunidades do Lago estão associadas à ACORJUVE." (WANDERLEY, 2012, p. 75). 